\title{
An integrated dynamic design system for aerostatic spindle development
}

\author{
Wanqun Chen ${ }^{1,2}$, Yingchun Liang ${ }^{1}$, Xichun Luo ${ }^{2 *}$, Wenkun Xie ${ }^{1,2}$ \\ 1.Center for Precision Engineering, Harbin Institute of Technology, Harbin 150001, P. R. China \\ 2. Department of Design, Manufacture \& Engineering Management, University of Strathclyde, Glasgow, G1 1XQ, UK \\ Email:Xichun.Luo@strath.ac.uk
}

\begin{abstract}
In this paper an integrated dynamic design and modeling system is developed for aerostatic spindle development. This system integrates initial structural design, bearing stiffness computation and the spindle dynamic performance prediction. Modal fitting is used to transform the finite element model into a two-degree-offreedom system model, which will make it easier to control the system and calculate the dynamic response. The design system is implemented by using commercial software, such as Pro/E, Matlab and Ansys. Consequently, the integrated dynamic design system enables the designers to costeffectively complete structural design of an aerostatic spindle. A case study has been presented in this paper for design of an aerostatic spindle used for flycutting. The machining results demonstrate the effectiveness of the developed integrated dynamic design system for aerostatic spindles design.
\end{abstract}

Keywords- aerostatic spindle; design system; machine dynamics; integrated design

\section{INTRODUCTION}

Spindle is one of major mechanical components in a machining center. The static and dynamic stiffness of the spindle directly affect the machining productivity and machined surface finish of the workpieces [1]. Nowadays, aerostatic spindles are widely used in the precision and ultra-precision machine tool because of the advantages such as lower heat generation, lower wear and friction, lower noise, less contamination and higher precision [2-4].

Significant researches have been carried out in the field of analysis of static and dynamic performance of the spindle. Cheng et al. investigated the performance of high speed spindle aerostatic bearings and the effects of the gas supply pressure, orifice diameter, gas film thickness, and eccentricity ratio upon the load capacity, stiffness, and volume flow rate change of a journal bearing operated at different rotational velocities [5]. Ingle et al. studied the static and dynamic performance characteristics of the carbon-epoxy shaft in aerostatic conical journal bearing at high speeds [6]. But there is few literatures illustrate the aerostatic spindle meticulously and systematically from the structural design to parameters optimization and performance prediction.

In this paper, an integrated dynamic design system is presented for the development of aerostatic spindle. The overall integrated dynamic design system is outlined in Fig.1. The system links the spindle structure design, bearing parameters optimization and dynamic performance prediction together which makes the aerostatic spindle design efficient and systematic.

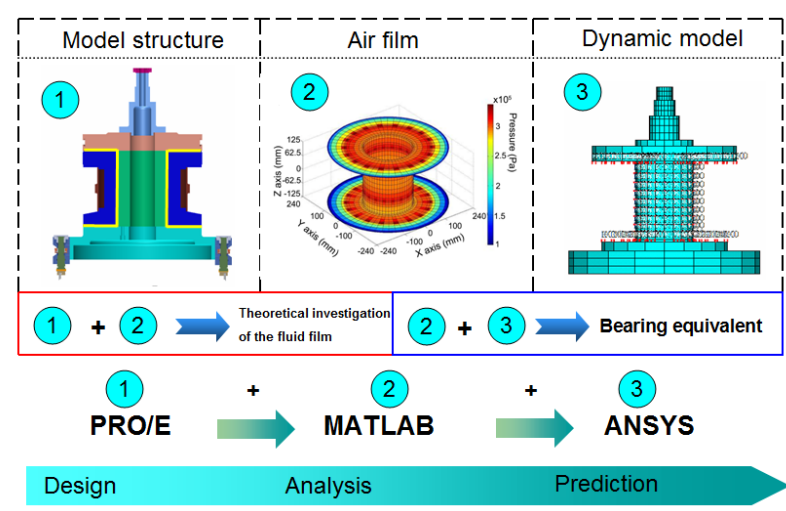

Fig.1 The outline of integrated dynamic design system

\section{INTEGRATED DYNAMIC DESIGN SYSTEM}

Conceptual design and performance evaluation can be done very effectively through using computer aided design tools. Core elements of this initiative are: select the most appropriate structural type, create reasonably detailed concepts with 3D computer aided design systems, compute the stiffness and pressure distribution of the bearing and model the accurate FE model. In this system, all of the design parameters are parameterized, so that they can be changed conveniently, resulting in shorter time of design and manufacture and lower cost.

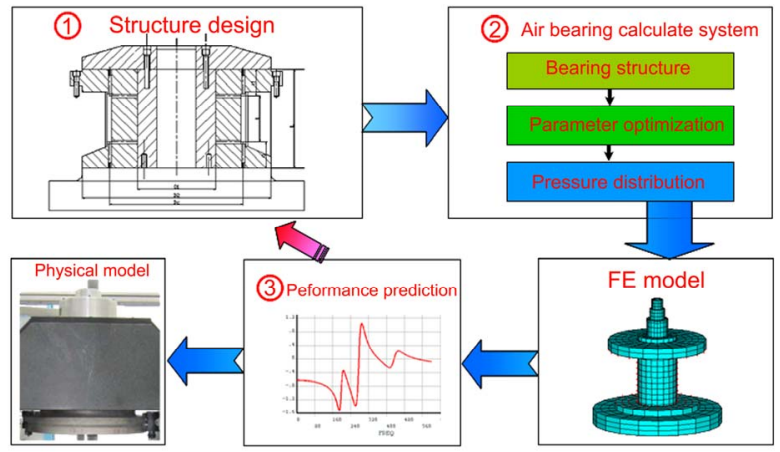

Fig.2 The design process of the system

As illustrated in Fig.2, the system can be described by the following steps:

Step 1. The structure design of the spindle. In this step, the designer decides the structure type of the spindle according to the performance requirement and gives the 
initial structure parameters such as the diameter and length of the shaft, the diameter of the orifice and the value of clearance of the air film in the $3 \mathrm{D}$ modeling software e.g. Pro/E.

Step 2. The bearing stiffness computation and design parameters optimization. The structural parameters of the air film are extracted from the spindle structure, and transmitted to the Matlab. The diameter of the orifice and the clearance, which are the two critical parameters of the aerostatic bearing are selected as the design variables and optimized automatically. The bearing stiffness is an important issue for bearing design as it may bring the system to instability and becomes a common limitation to productivity and part quality [7-9]. Therefore, the bearing stiffness is selected as the objective function. The objective function $\left(f_{o b}\right)$ is simply defined as follows:

$$
\text { Maximum: } \quad f_{o b}=f\left(x_{1}, x_{2}, \cdots, x_{n}\right)
$$

where $x_{i}$ is the structural parameters of the bearing. Thus, the clearance and the orifice diameter are set as the design variables and the Quadratic Interpolation (QI) method is adopted to optimize the spindle design. The finite difference method is used in this step to get the pressure distribution in the bearing. An equivalent spring elements group is generated based on the pressure distribution, which can improve the bearing simulation accuracy greatly.

Step 3. The spindle dynamic performance prediction. The finite element model of the whole aerostatic spindle is assembled by the aerostatic bearing equivalent spring elements group and the shaft model. Next the performance prediction of the spindle designed is carried out. If the dynamic performance predictions satisfy the design requirements, the structural parameters are used as the final design parameters. But if the dynamic performance prediction is not satisfied the design requirements, for example, if the designer want to design an aerostatic spindle with the first order natural frequency of $200 \mathrm{~Hz}$, but the dynamic performance prediction does no satisfy the design requirements, it indicates that the current structure of the spindle is unreasonable. It must be changed, the diameter and the length of the spindle should be increased. Then it will be followed by step 1 , and then by circulation until the dynamic performance prediction satisfied the design requirements.

\section{APPLICATION OF THE AEROSTATIC SPINDLE DESIGN SYSTEM}

Take the design of the aerostatic spindle used for KDP machining as an example. Considering the processing conditions in flycutting, the angular stiffness and the dynamic performance have an important influence on the machining performance[10,11]. Therefore, the design requirements are put forward as follows: the angular stiffness larger than $600 \mathrm{Nm} /$ arcsec and the first natural frequency not less than $100 \mathrm{~Hz}$. In order to have a large angular stiffness, the structure type of the spindle is designed with two larger thrust plates. The initial parameters of the spindle structure are given in the structure design stage as shown in Fig.2. Then the structure parameters of the air film are extracted from the spindle structure, and transmitted to the Matlab. The diameter of the orifice and the clearance are optimized automatically. The optimization process contains two steps: 1 . The orifice diameter is fixed at $0.2 \mathrm{~mm}$, and the trends of the stiffness are obtained with different clearance. It can be noted that the stiffness in each direction primarily increases and decreases with the clearance increasing. As shown in Fig.3, the maximum stiffness in axial, radial and angular are all obtained at $15 \mu \mathrm{m}$. Therefore, the $15 \mu \mathrm{m}$ is selected as the bearing film gap. 2 . The clearance is fixed at $15 \mu \mathrm{m}$, the trends of the stiffness are obtained with different orifice diameters. From Fig.4 it can be noted that the optimization parameters of the aerostatic bearing are that the clearance is fixed at $15 \mu \mathrm{m}$ and the orifice diameter is $0.15 \mathrm{~mm}$. And the axial, radial and angular stiffnesses are $2188 \mathrm{~N} / \mu \mathrm{m}, 640 \mathrm{~N} / \mu \mathrm{m}$, and $1167.5 \mathrm{Nm} /$ arcsec, respectively. The pressure distribution of the aerostatic bearing with such parameters is given by the bearing analysis system.

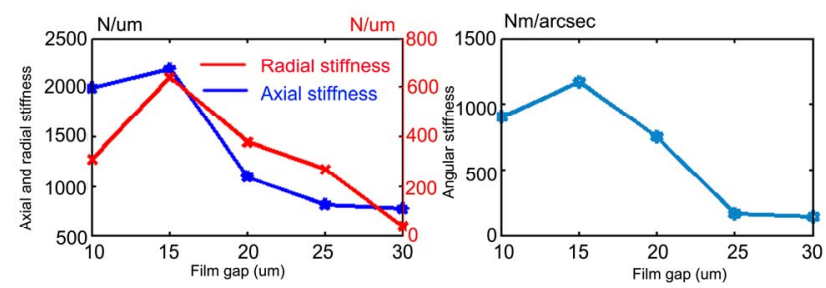

Fig.3 The film gap optimization of the bearing

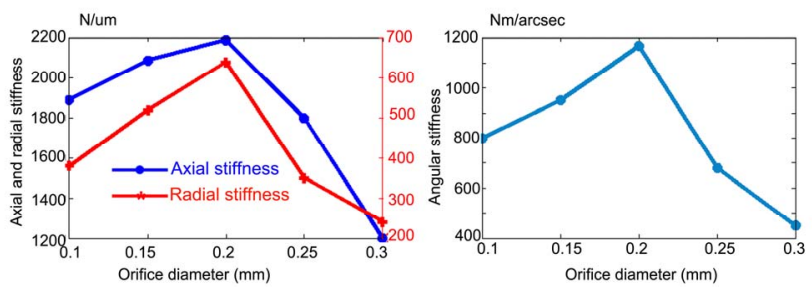

Fig.4 The orifice diameter optimization of the bearing

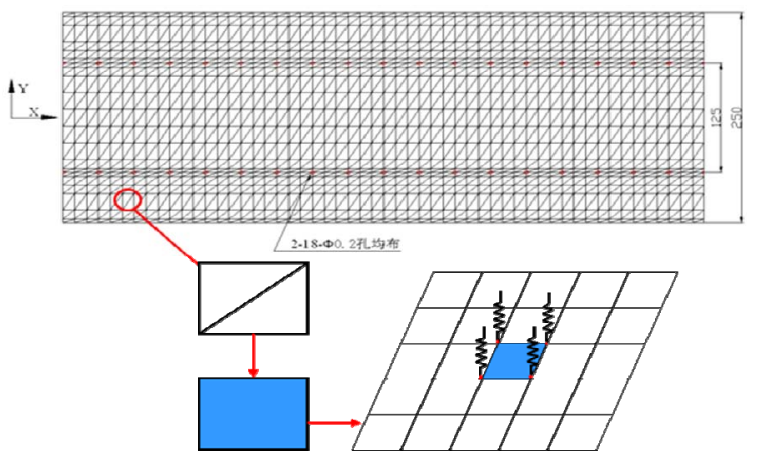

Fig. 5 The transfer process of the pressure distribution information into a equivalent spring distribution

Then an equivalent spring elements group is generated according to the pressure distribution of the aerostatic bearing[12]. The pressure of each element in the air film is equivalent by the spring elements in the nodes of the elements, as shown in Fig.5. Therefore, each spring element has different real constant, which determine the stiffness of the locality. The equivalent spring elements group coupling the shaft and shaft sleeve together, 
constitutes the finite element model of the spindle, as shown in Fig.6.
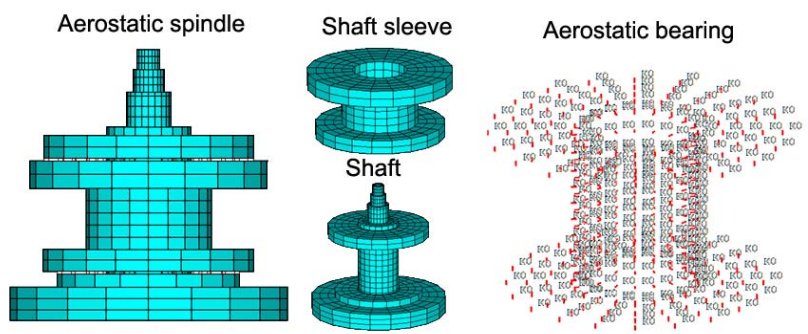

Fig.6 The FE model of the aerostatic spindle

The dynamic analysis is carried out in the dynamic analysis system. Fig.7 shows the dynamic response curves of the whole spindle system. The dynamic stiffness of the aerostatic spindle can be obtained as shown in Fig.7. The control loop demonstrates $1 \mathrm{kHz}$ bandwidth, and in the whole bandwidth it has three poles and zeros. In the frequency range $0-100 \mathrm{~Hz}$, the system works in the quasistatic region, the stiffness is $148.8 \mathrm{~N} / \mu \mathrm{m}$, and it has the smallest dynamic stiffness $40 \mathrm{~N} / \mu \mathrm{m}$ at $276 \mathrm{~Hz}$. To control the system and calculate the dynamic response, we hope that the system is a second-order system which we are familiar with, rather than a complex finite element model. Therefore, in this paper the finite element model is transformed into two-degree-of-freedom system model. In order to obtain the simple but accurate dynamic equations of the system, the modal fitting is used to obtain the modal parameters through the "peak-picking" method based on the dynamic response curves of the system. The advantage of this method is that the decoupled FRF can be obtained directly, which avoids the cumbersome process of decoupling. In addition, the decoupled dynamic parameters are extracted from the FE model, which are more accurate than lumped mass method. Then the aerostatic spindle is simplified to a two-degree-of-freedom system and we can solve this system conveniently.

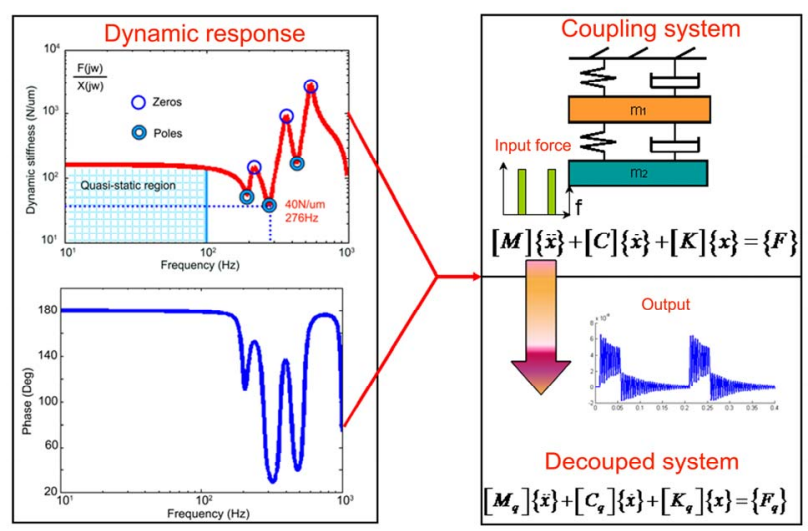

Fig.7 The dynamic performance prediction of the spindle

\section{MACHINING TRIALS ON THE AEROSTATIC SPINDLE}

The aerostatic spindle for the fly-cutting machine is designed according to the design parameters optimized by the design system. The machining trials are carried out on an aluminum block sized $415 \times 415 \mathrm{~mm}^{2}$ under the following processing parameters: a depth of cut of $15 \mu \mathrm{m}$,a feed rate of $60 \mu \mathrm{m} / \mathrm{s}$ and a spindle rotational speed of 300 $\mathrm{r} / \mathrm{min}$. The machined surface is shown in Fig.8. The test results shown in Fig. 9 and Fig. 10 are examined by a 3D surface profiler Wyko RST-plus (Veeco Metrology Group, Santa Barbara, CA, USA). The test results show that the surface has a flatness of $0.8 \mu \mathrm{m}$ and an average roughness of $2 \mathrm{~nm}$ rms. It provides the evidence of the feasibility and robustness of the proposed aerostatic spindle design system.

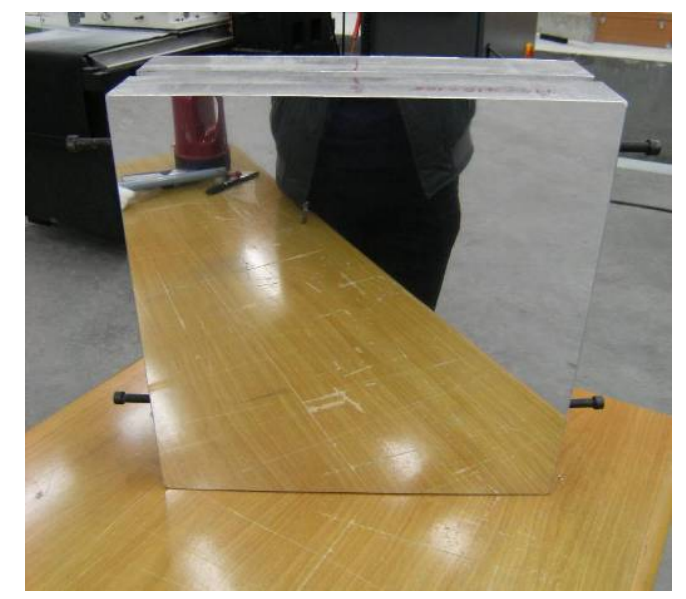

Fig. 8 The result of the machined surface

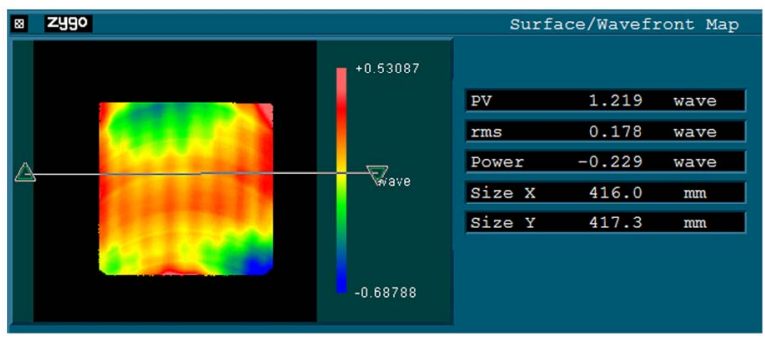

Fig.9 The flatness test result of the sample

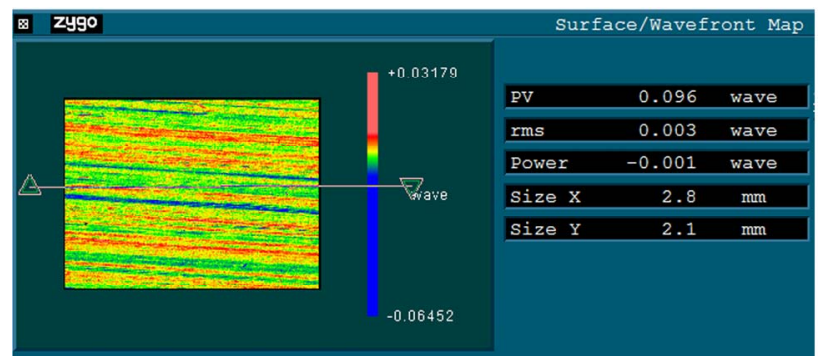

Fig.10 The roughness test result of the sample

\section{CONCLUSIONS}

This paper presents an integrated dynamic design and modeling system used for aerostatic spindle design. The following conclusions can be draw.

1. A systematic design system is proposed to integrate the structural design, static and dynamic bearing stiffness computations and the spindle dynamic performance prediction. This design system can be used as a powerful tool for supporting the full design process for aerostatic spindle in terms of dynamic design. The simulations based on the approach is very useful to support the full design process in an iterative manner, which enables the spindle design to be optimized effectively. 
2. The proposed modal fitting is very effective in transforming finite element model into a two-degree-offreedom system model, which eases the system control and dynamic response calculation.

\section{ACKNOWLEDGMENT}

The authors gratefully acknowledge financial support of the National Science and Technology Special Program (grant number 2011ZX04004-041), The Sino-UK Higher Education Research Partnership for $\mathrm{PhD}$ Studies program, and China Scholarship Council (CSC).

\section{REFERENCES}

[1] O. Maeda, Y. Cao and Y. Altintas," Expert spindle design system," Int J Mach Tools Mf 2005; 45(4-5): 537-548.

[2] S. M. Chun. "Aeration effects on the performance of a turbocharger journal bearing," Tribol Int 2008; 41(4): 296306.

[3] W. B. Rowe. Hydrostatic, aerostatic and hybrid bearing design. Oxford: Butterworth Heinemann; 2012.

[4] X. D. Lu, M. P. Paone, I. Usman, et al. "Rotary-axial spindles for ultra-precision machining," CIRP Ann 2009; 58(1): 323-326.
[5] Y. L. Cheng, C. C. Wang and Y. H. Lee, "Performance analysis of high-speed spindle aerostatic bearings," Tribol Int, 2005; 38(1): 5-14.

[6] R. B. Ingle, B. B. Ahuja, "An experimental investigation on dynamic analysis of high speed carbon-epoxy shaft in aerostatic conical journal bearings," Composites Science and Technology, 2006; 66(3-4): 604-612.

[7] W. B. Rowe, "Hydrostatic, aerostatic and hybrid bearing design," Oxford: Butter-worth-Heinemann; 2012.

[8] E. Abele, Y. Altintas, C. Brecher, "Machine tool spindle units," CIRP Ann: Manuf Techn 2010; 59(2): 781-802.

[9] W. R. Wang, C. N. Chang, "Dynamic analysis and design of a machine tool spindle-bearing system," J Vibr Acoust 1994; 116(3): 280-285.

[10] H. X. Wang, W. J. Zong, T. Sun, et al. "Modification of three dimensional topography of the machined KDP crystal surface using wavelet analysis method," Applied Surface Science 2010; 256(16): 5061-5068.

[11] Y. C. Liang, W. Q. Chen, Y. Z. Sun, et al. "Dynamic design approach of an ultra-precision machine tool used for optical parts machining," In Proceedings of IMechE Part B J Engineering Manufacture 2012; 226(11): 1930-1936.

[12] Y. C. Liang, W. Q. Chen, Y. Z. Sun, et al. " An expert system for hydro/aero-static spindle design used in ultra precision machine tool" Robotics and Computer-Integrated Manufacturing 2014; 30(2): 107-113. 